\title{
Remembering the city: Changing conceptions of community in urban China*
}

Dr Andrew Manley

University of Bath, UK

Professor Michael Silk

Bournemouth University, UK 


\title{
Remembering the city: Changing conceptions of community in urban China
}

\begin{abstract}
Adopting complimentary integrative research methodologies, this article examines changing conceptions of community amongst urban residents within the city of Suzhou, Jiangsu province, China. Whilst the impact of urban transformation from a macro-perspective, deploying large scale quantitative measures to capture resident perceptions within China's mega-cities, has been addressed, there is something of a scholarly lacuna that adopts a micro-perspective to explore the nation-state's smaller developing cities. Thus, through local residents' past memories, 'everyday' experiences of (former) urban communities, and reflections on a particular way of life, we focus upon the subjective/affective meanings and memories attached to processes of urban change. We place emphasis on the manner in which residents make sense of socio-spatial transformations in relation to the (re)making of community, local social interaction, and a sense of belonging. Discussion centres on the affective and embodied notions of a particular way of life in (older) communities; sensory performances that were deemed difficult to replicate within modern development zones and the broader field of contemporary Chinese society.
\end{abstract}




\section{Remembering the city: Changing conceptions of community in urban China}

If the landscape changes, then I don't know who I am either. The landscape is a refracted autobiography. As it disappears you lose your sense of self (Iain Sinclair in Jones 2015: 13).

Following market reforms instigated by Deng Xiaoping in the post-Mao era, China has witnessed an unparalleled acceleration in economic growth and is currently experiencing a rapid and concentrated rise in urban development (Logan 2008; Wu 2012). The redevelopment of urban residential areas - and the influx of migrant populations seeking employment in cities that have attracted both global and domestic investment - has transformed the social infrastructure of urban neighbourhoods and re-shaped differing conceptions of 'community' (Forrest and Yip 2007; Wu 2012; Wu and He 2005). Scholarship examining the rapid rate of urban growth across Asia has tended to emphasise the increased importance of gaining access to historical memories of place, and the continual role that such a process plays in the making of 'community', and how old place names/memorial landscapes, inscribed with collective memories, aid in the construction of place based identities and attachment (Li, Hong, and Huang 2010; Pan 2003; Zhu, Chen and Qian 2014). However, the recalling of past memories, embodied experiences, nostalgia and reflections upon former urban communities has become increasingly overlooked in recent studies examining China's urban transformation and community interaction/engagement (He and Qian 2017; Zhu et al. 2014). This is important, as capturing the complexities of urban memories can have multiple impacts, not limited to: the continuity of urban history, community, and belonging; the shaping of urban spirit and culture; a strengthening of the identity and cohesion of urban residents; the destruction of built history and the eradication of community memories, and offer targeted guidance to city planners and authorities in future development (Adams and Larkham 2015; Rose-Redwood, Alderman and Azaryahu 2008). 
Thus, our focus in this paper is on the ways in which residents make sense of these urban transformations in relation to the making or re-making of community, local social interaction and a sense of belonging. Here the concept of community is understood as representative of the collection of people, institutions and cultural, political and ecological forces they possess, consisting of a set of practices, common habits and traditions inherited from previous generations and cultural influences, never isolated nor detached, but rather situated within larger communities connected through economic and political ties of interdependency (Park 1915, 1925; Wirth 1925). In asserting this definition of community our understanding of neighbourhood refers to the social and political organisation of the city itself, formed of local interests and associations and consisting of the tensions and sentiments that provide the neighbourhood with its character (Park, 1915). Viewed as fluid and diverse spaces, communities are engaged in a process of continual alteration that is closely aligned with, or reacting in response to, wider socio-political and economic arrangements implemented to govern strategies of urban growth.

Scholarship examining neighbourhood attachment and socio-spatial transformation in Chinese urban residential areas has pointed towards a diversification, differentiation and segregation in, and between, differing neighbourhoods, resulting in the decline of local interaction among neighbours and the weakening of social ties (Forrest and Yip 2007; Lewicka 2008; Liu, Li and Breitung 2012; Pow 2009; Wu 2010; Yeh, Xu and $\mathrm{Hu}$ 1995). Yet, despite recent research focusing on community participation, development and intergroup neighbouring in urban China (Xu and Chow 2006; Xu, Perkins and Chow 2010; Wang, Zhang, and Wu 2015), there exists a lack of understanding regarding residents' sense of community (and community engagement), patterns of social interaction and their relationships with the rapid, and somewhat unapologetic, process of urban transformation and development (Forrest and Yip 2007; Wu 2012). Indeed, existing scholarship has tended to examine urban China in response to the impact of economic globalization and the spatial reconfiguration of many of the nation's megacities (e.g. Shanghai, Beijing, 
Guangzhou); this has, more often than not, employed a macro-perspective, capturing resident experiences through large scale quantitative analyses (e.g. Li et al. 2012; Ren 2008; Yip 2012). Thus, there exists a lacuna of empirical evidence adopting a 'microscopic' perspective (focusing for example on specific places such as the city, the district, the street, and the house, see Lewicka 2008) that can expose, and aid understanding of, the cultural constraints and behavioural patterns tied to China's current philosophy of urban reform (He and Qian 2017; Ren and Luger 2015; Wai 2006; Wu and Ma 2006). Such work is especially important given it is generally agreed that emotional and social bonds with 'place' is a pre-requisite of psychological balance, stability, identity, attachment and involvement in local social/leisure activities (Lewicka 2008).

To fill this scholarly gap, we deploy a number of complimentary integrative research methodologies to provide rich, empirically driven, accounts of community and belonging under planned processes of urban transformation. The data is drawn from residents from differing urban neighbourhoods - an area of older, inner city housing and heritage protected buildings, and a newer area of commodity-housing - in Suzhou, a tier-two city located in Jiangsu Province China. As a site for research Suzhou holds great relevance as there is a dearth of empirical work conducted on the wide spread urban redevelopment of China's smaller tier-two cities (Zhu et al. 2014). Insight into the manner in which social actors negotiate the lived dimensions of urbanisms outside China's mega-cities may provide a unique focus upon the complex, and perhaps incidental, cultural meanings and social processes that connect the social and the spatial (Zhu et al. 2014). Our analysis focuses on understanding residents' reflections on their past communities in relation to intensified urban (re)development. This offers insight into the altering patterns, and loss of, 'local' social interaction, whilst providing an explorative insight into notions of community through the lens of urban memory. 


\section{Compounds, Community and Belonging in Urban China}

A brief genealogy of China's housing and neighbourhood communities can be delineated through distinct periods of political transformation and attendant economic, housing and urban land reforms. Prior to the socialist transformation of the People's Republic, China's urban neighbourhoods were characterised by courtyard housing, narrow alleyways and building compounds designated for a specific social establishment, whereby institutions such as local government offices, temples and schools formed an integral element of a larger composition ( $\mathrm{Li}, \mathrm{Zhu}$ and $\mathrm{Li}$ 2012; Xu 2000). Thus, individual structures were closely associated with social institutions and considered meaningful only in relation to their role with other buildings and structures (Xu 2000). Under state socialism, urban residential areas were largely developed by individual workplaces, reorganising urban neighbourhoods in accordance with the ideology of productive functional citizens and the construction of work-units, or danwei compounds. These compounds were designed to integrate residential living within the workplace, successfully stimulating a 'compound culture' that formed close social-ties and a strong sense of community belonging between workers and other danwei families (Li et al. 2012; Wang and Murie 1999). During the post-Mao era, and under the implementation of market-oriented economic reforms - albeit with distinct Chinese characteristics (e.g. Arrighi 2007; Ding 2004; Harvey 2005; Huang 2008; Liew 2005; Ren 2013)—the transition from a socialist centrally planned economy to that of a socialist market economy has had a profound effect on urban communities within contemporary China. The encroaching processes of privatization, marketization and deregulation have shifted China's cartographic footprint towards an urban conurbation that has usurped, if not fully replaced, the rural and agricultural sectors, restored private control over land use, and established housing as a free-market commodity (Wu 2006). This has resulted in the spatial, social and economic restructuring of the Chinese cityscape, a process intimately tied to forces emanating from different geographical scales ranging from the global, 
national, and, the local (Wu and Ma 2006). A subsequent large-scale redevelopment of inner-city areas has resulted in the clearance of pre-1949 neighbourhoods and danwei communities, giving rise to commercial complexes and high-rise apartment compounds that often reach into the urban peripheries. Partly fuelled by the aspirations of a burgeoning middle class and their desire to invest in property, this concomitant urban sprawl has resulted in the rapid growth of gated commodityhousing estates in newly developed suburban districts-alongside parts of inner-city neighbourhoods - that have transformed and reshaped notions of community, neighbourhood attachment and contemporary conceptualisations of civic identity (Douglas, Wissink, and Van Kempen 2012; Li et al. 2012; Pow 2009).

The rise of commodity-housing estates has contributed towards an accelerated level of enclave urbanism, where gated communities act to divide — both physically and discursivelycityscapes into select parcels of urban space that (re)produce exclusive class-based identities and lifestyles closely aligned with the wider logics of neoliberal urbanism and transnational gentrification (author 2004; 2007; in press; Douglas et al. 2012; Pow 2009; Shen and Wu 2013; Sigler and Wachsmuth 2016; Zhang 2010). As separate and self-contained communities, gated commodity-housing estates are easily distinguishable in relation to older urban spaces, in some instances mimicking Western style architecture, and constructed in response to viewing urban (re)development as an avenue for capital accumulation and the (re)production of spaces for consumption (He and Wu 2005; Wu 2009). The desire to reside in gated neighbourhoods becomes increasingly associated with notions of privacy, security and access to a privileged, idealised, lifestyle that aligns with 'low density', environmentally sustainable and luxurious living (He 2013, Douglas et al. 2012; Wu 2010). As such, there can be observed a concerted fragmentation of community, and a palpable loss of continuity with the past, group traditions, and (historic) place attachment within China's urban neighbourhoods. 
There exists however limited empirical understanding of the establishment of 'community' within such compounds. Some (e.g. Xu 2008) point to the exclusionary nature of gated commodityhousing estates, whilst others have highlighted the complex configurations that exists between the social fabric and urban form of China's developing cityscapes (He 2013). Indeed, the presence of new residential enclaves does not immediately inhibit contact amongst diverse population groups, nor should residential places be considered the only locale for social encounters or community interaction (Douglas et al. 2012; Li et al. 2012; Wang, Li and, Chai 2012). Furthermore, there exists a variance in housing types situated within large-scale Chinese estates_ranging from lower middle class to exclusive- - that differentially are designed to encourage interaction between a range of social groups (Yip 2012). Likewise, high levels of intergroup neighbouring activities can be witnessed amongst those residing in traditional courtyard housing promoted through access to shared and semi-public spaces (Wang et al. 2015). The co-existence of historic and developing neighbourhoods forms a complex urban assemblage that Shen and $\mathrm{Wu}(2011: 273)$ describe as a "restless landscape." It is in this sense that China's conception of urban development is evolving through a course of constant 'unfolding' (Deleuze 1993), an emerging process of transformation and dispersion that generates new encounters between actors and their surroundings, inventing connections and disrupting patterns of everyday urban life (Anderson and McFarlane 2011; McFarlane 2011). To explore this unfolding urban assemblage we turn to what we consider to be an emblematic exemplar, the city of Suzhou.

\section{Suzhou: The City as Assemblage}

Located northwest of Shanghai and encompassing a total area of approximately $8488.2 \mathrm{~km}^{2}$, Suzhou is a prefecture-level city ${ }^{1}$ and the second largest in Jiangsu province with an established

\footnotetext{
${ }_{1}$ Prefecture-level cities in China hold less administrative power than the provisional (e.g. Shanghai) and subprovisional cities (e.g. Nanjing), yet more than county-level cities. In the case of Suzhou, the surrounding countylevel cities would include Kunshan, Wujiang, Changshu, Taicang and Zhangjiagang (Wang et al. 2015)
} 
commerce sector and a rapidly emerging research and development industry. Unlike many of its compatriot cities Suzhou has implemented urban planning strategies that actively seek to conserve and protect its built heritage. Situated at the heart of the city and enclosed by a moat lies the historical district, or 'old town', a $2.5 \mathrm{~km}^{2}$ designated 'protected zone' that contains a number of World UNESCO heritage gardens, ancient canals, bridges, temples and resident buildings. In a bid to capitalise on the economic gain of tourist footfall, Suzhou's spatial planning policies have attempted to improve the public infrastructure of the 'old town', retain its indigenous residents and preserve, manage and promote the rich (in)tangible cultural heritage of the city (Wang et al. 2015).

Despite stated intentions to protect and preserve both the human and built constituents of Suzhou's 'old town', the city's pattern of urban (re)development and spatial reconfiguration has proceeded in a complex manner guided by state intervention, Foreign Direct Investment (FDI) and the manipulation of local development conditions (Wang et al. 2015; Yang and Wang 2008). In the late 1980s, initial attempts to promote Western investment within Suzhou attracted limited foreign attention and trade; the city maintained a growth strategy positioned toward the domestic sector and state owned enterprises (Wei et al. 2009). In an attempt to further encourage FDI, leaders of the Chinese and Singaporean government announced in 1994 the arrival of a jointly developed industrial park to be located on the fringes of Suzhou. The collaborative creation of the Suzhou Industrial Park (SIP) provided a more transparent and efficient mode of bureaucracy for overseas investors and encouraged foreign firms to establish a presence within the district, rapidly accelerating the city's economic growth and transforming the development zone from an area of industrial focus to an area incorporating commodity-housing complexes, commerce, recreational and educational establishments (Wang et al. 2015). Following the early success of the SIP, Suzhou has continued to pursue the trend of growth through the implementation of further development zones supported by the municipal government, with each zone offered differing policies in association with land reform and taxation (Cartier 2001; Wang et al. 2015; Yang and Wang 2008). 
In its current guise Suzhou represents a rapidly expanding city consisting of fragmented districts each vying for the premier position to attract both global and domestic capital, readily identifiable by their emerging landscapes and fading reference to preceding eras of urban reform (Wang et al. 2015). Whilst capital accumulation, driven by the intermediation of private investment, may be perceived as the primary motivation behind China's urban (re)structuring, Suzhou's pathway of development, like many Chinese cities, follows a route entrenched in a multiplicity of complex interrelations, a process that demonstrates a growth-centred focus distinguished from the dominant neoliberal discourse primarily associated with a western-centric model of development. Of key importance is the central government's interventionist role in shaping the pathway of urban (re)development and the premature market system that is unable to overshadow or control the state (He 2009; He and Wu 2009; Wang and Liu 2015), a landscape that portrays China's engagement with neoliberal principles as akin to "a loose hug rather than an intimate embrace" (Liew 2005: 349). Encapsulated by a multi-scalar approach to growth and development, Suzhou represents a complex assemblage of institutional actors and organisations that seek to negotiate, contest and reconcile the powers and interests of differing levels of the state and affiliated corporate entities (Lin and Ho 2005; Yang and Wang 2008). In this regard, Suzhou's urban development can be viewed less as a singular resultant formation of economic liberalism and more as constituting an assemblage of multiple interdependent actors consisting of differing power relations, resources and determinations. Resultantly, Suzhou's contemporary form is an increasingly heterogeneous "mosaic of urban enclaves" (He 2013: 260), a composition of multiple actors, spaces and institutions emblematic of the dynamic systems of interaction and co-evolving governance projects, strategies, and practices - conceptualized within both national and transnational scales (McGuirk and Dowling 2009) — that work toward moulding China's urban form. To understand the manner in which actors have come to negotiate everyday urban life within a city encapsulated by multiple shifting relations, and the creation of new forms of urban space and collectivities, emergent identities and social 
behaviour (McFarlane 2009, 2011), we turn to the role of urban memories. In so doing, we elicit a range of (contemporary) urban pasts providing insight into changing relations with, and understandings of, community and a sense of belonging.

\section{Memory, Nostalgia and Affect}

If social memory and social space conjoin to produce much of the context for (and contestation of) modern identities (Hoelscher and Alderman 2004; Farrar 2011), it follows, building on Halbwachs (1980), that sites of memory hold communal identities together and that the spatiality of memory links the social and the personal (Crang and Travlou 2001). Thus, with Dwyer and Alderman (2008: 165), "landscape and memory are mutually constitutive of one another", and as such, the importance of acquiring insight into personal recollections of the past, concepts of place and notions of community becomes increasingly important in cities undergoing rapid urban transformation. Nostalgia and the recovery of social memories evokes the uneasiness with which individuals seek to reconcile attachment to a sense of place, community or expression of identity, and further provides the potential to unearth narratives to which one may gain a clearer understanding of how people cope with the present and imagine the potentialities of a particular future (Lowenthal 1975, 1985; Mills 2006). As a social activity, memory maintains the capability to represent an expression of group identity, bind communities and, through critical reflection, reveal wider cultural and societal shifts that impact upon connections to place and a coherent sense of belonging (Edensor 1997; Hoelscher and Alderman 2004; Said 2000). As such, urban landscapes are comprised of a complex terrain that constitute, and come to express, a shifting (inter)relationship between people, place and activities. This is perhaps of particular resonance in areas of urban sprawl in which architectural amnesia can create a nostalgic longing for a past place—real or imagined (Farrar 2011) ${ }^{2}$.

\footnotetext{
${ }^{2}$ As Farrar (2011) indicates, the typical response or antidote to such loss is historic preservation; a strategy fraught with politics over whose histories are preserved, whose are forgotten, the power relations inherent in remembering (and forgetting) and the capitalization of such areas for capital accumulation such that they become areas for tourists rather than locals.
} 
However, there have been few studies that have evoked methodologies that can understand how places and sites of memory—-beyond their forms as authored representations of the past—are experienced affectively by individuals and social groups (Till 2012). That is, there has been a paucity of approaches looking to "analyse how transgenerational encounters, performances, and rituals transmit and circulate understandings about the past across historical and lived times and through social spaces" (Till 2012: 7). This aberration is a concern given that such work can offer possibilities across generations that can build self-worth, social capacity, create social capital, provide space for intergenerational education, and offer stability and security within the accelerated ruptures of "growth", displacement, and exclusion. Thus, greater emphasis must be placed upon capturing the nuances and textures of "urban memories", those that are shaped by personal sentiment, social circumstances and the mundane and everyday subtleties that come to guide the intimate experiences of urban life (Bell 2003; Chang 2005). The historical memory of place continues to play an integral role in the making of 'community', and we must seek to place greater emphasis upon collecting the personal memories that come to inform a sense of place and belonging. Oral histories and the expression of nostalgia provide a bridge to the past that can evoke a sense of continuity for individuals and communities, eliciting the manner in which residents actively engage with, and reflect upon, processes of urban change (Bartmanski, 2011). With emphasis upon the emotive reactions towards transforming communities, urban growth and rapid neighbourhood reconfiguration, we may better understand the force of local tradition and its relationship with material structure influencing the habits, feelings and remembrances of residents connected to a specific place or space (Halbwachs, 1980). Such an approach maintains the capacity to enhance our continued understanding of the dynamic relationship between people and the physical environment, specifically focusing upon the disrupted usage and way of life that guides individuals' interpretation of emerging and contemporary city space (Adams, 2011; Fenster and Misgav, 2014). Thus, the importance of acquiring empirical insight into personal recollections of 
the past and the concepts of place, memory and community are becoming increasingly important to cities undergoing rapid transformation, whereby notions of the past are under threat of distinction, caught up in a process of reformulation (Chang 2005; Pan 2005).

Through seeking out the 'small' and striving to understand, and engage with, the subjective meanings that individuals make in, and from, social memories connected to practices of the past, our intent is to forward clearer understandings of historic and contemporary conceptions of community interaction (DeLyser 2004). Within this paper, we aim to contribute towards such possibilities via explication of the dynamics, (dis-)continuities and centrality of urban memory.

\section{Research Methodology}

To comprehend changing community relations, we utilised a series of complimentary integrative research methodologies that brought together resident interviews, (historic) photo elicitation, walking ethnography, and document and image analysis. These offered a robust and rigorous empirical data set that formed the basis for a conceptual analysis of the lived experiences of community within the urban assemblage. Within this paper we draw specifically on resident interview data, photo elicitation and walking ethnography. ${ }^{3}$

Walking, as a practice, has had a relatively long history in ethnographic work/urban theorising; although it is only recently that it has been conceived as a methodological concern that can offer new ways of learning/of coming to know as we walk (Pink, Hubbard, O’Neill and Radley 2010; Edensor 2010). As an approach to aid understanding of the multi-sensory nature of experiences of urban aesthetics (Latham and McCormack 2009), we combined walking with photography. This approach enabled us to collect detail on urban life and framed walking as a "process of orientations/reorientations and attractions/distractions" (Y'ien 2013: 3) that focussed

\footnotetext{
${ }^{3}$ Data from the wider project (including elite interviews with municipal and provincial actors and complimentary methodologies) are being further developed elsewhere in articles focused on heritage preservation/exploitation, duplitecture, and transnational gentrification.
} 
the lens on objects-in place, aiding us to "disentangle the often-ignored materiality from its urban fabric" (Y'ien 2013: 4).

As part of a cyclical methodological process, over the course of multiple visits over 15 months, we used images as "openings for imagination" (Y'ien 2013) in resident interviews, and allowed the voices of our interviewees to further guide us in where, when and how to walk as we returned to, revisited or found new places to walk. In this sense, the images were used as stimulants to evoke comments, personal memories and in-depth discussions that focused upon the participants' experiences of neighbourhood transformation and community interaction (Liebenberg 2009). In particular, photo elicitation (Rose 2013) served as a basis for discussion surrounding specific neighbourhoods or structures, added clarity to vague memories, encouraged rapport between the interviewer and interviewees and allowed participants to elaborate on key aspects of community life in rich detail (Banks and Zeitlyn 2015). Photo-elicitation interviewing promoted an environment conducive to longer and more comprehensive interviews that enhanced remembering, stimulated new thoughts and offered a unique way to convey lived experiences located in both the past and present (Matteucci 2013).

Active interviews - that encouraged deviation from any set schedule (Holstein and Gubrium 2003) - took place in the homes of local residents situated in either the former danwei compounds or modern gated-commodity housing estates. Those interviewed had lived in Suzhou their entire lives and had all experienced, and could reflect upon, a time in which they resided within the city's old town district ${ }^{4}$. The integrated methodology allowed for us to generate sensory data (Pink et al. 2010) and framed an especially effective, collaborative approach that other methods likely would not have elicited. Indeed, we would argue the approach aided in reducing power imbalances in these qualitative methodologies - an especially important point given our own subject positionalities and

\footnotetext{
${ }^{4}$ Sampling was purposive and snowballed, informed consent was gained, interviews lasted between 40 minutes to three hours, and interviewees ranged from their early thirties through to their mid-seventies. In total, we interviewed 12 subjects, the majority on a number of occasions as part of the integrated design. In total, 21 interviews were conducted.
} 
negotiations over communication and enhancing cultural understandings and representations ${ }^{5}$ —and situated participants as authorities on their lives and in better control of the research process and content (Liebenberg 2009).

The use of photographs during interviews was particularly effective for discussion of alterations to Suzhou's urban landscape. In some instances, this led to local participants/residents going to a cupboard or box under the bed and bringing to the table (literally, given interviews took place around communal kitchen tables in residents' homes with welcoming green tea) their own personal collection of historic photographs as a means to elaborate upon key details linked to their memories of city life and former urban housing. By introducing the researchers' photographs of modern Suzhou to the interview context, local residents took this opportunity to share historic images of the city and use both as visual itineraries to connect certain stories and life histories that elicited intimate dimensions of the social, provided a unique way to communicate aspects of their current/former lives and created an environment that lessened any possibility of awkwardness (Clark-Ibáñez, 2004). Through acquiring insight into the life histories of residents and their experiences of a changing cityscape, questions concerning the importance of community and its impact upon a 'sense of belonging' could be understood. Such an approach was pursued for the purpose of identifying how projects of urban development have intervened upon specifics aspects of daily life, providing a clearer depiction of the values and qualities that have shaped perceptions of neighbourhood attachment and interaction between residents.

\section{Communal Living}

Typical neighbourhoods within Suzhou's old town contained an enclosed courtyard area, formed by the intersection of closely spaced resident buildings that offered a small opening to the sky above.

\footnotetext{
${ }^{5}$ We fully acknowledge the complexities and power relations at work in the conduct of such fieldwork by male, Western researchers with Chinese participants. As indicated, we attempted to counter these imbalances and align data with lived experience, through allowing participants control over data-gathering and interpretation. Likewise, via translation (a Suzhou native) and the moderate Mandarin language skills of the first author, all interviews were conducted in the Suzhounese Mandarin dialect.
} 
Aptly named sky wells, these public areas formed a communal space for daily interaction amongst residents. Upon recounting her memories of living within Suzhou's old town prior to the demolition of her neighbourhood, Yi Hu, a retiree in her mid-seventies, spoke of the former community, her daily interactions and the influence of courtyard housing upon creating strong social ties between residents and the wider community.

In the residential area we had a communal area, and several families living around, so lots of people used to spend a lot of time in the communal area chatting. And in the late afternoon you'd have people selling all sorts of things in the lane, you'd have people selling small huntun [won ton soup], and little bowls of congee [Chinese porridge], little snacks, so lots of things were going on in the lane.

Amongst many of the residents interviewed, Yi Hu's experiences of courtyard housing during China's socialist era reflected the close proximity, shared living spaces and intensive daily interactions that sought to develop a strong sense of connection despite the lack of actual familial ties (Huang and Low 2008). Moreover, the neighbourhood formed a space to create interaction between those outside the immediate community. The narrow lanes that intersected the sky well areas became meeting points to buy and sell goods, supporting local traders who lived nearby. Fu Rong, a retired accountant in her early sixties, also reflected upon the shared communal quarters and its role in promoting community interaction.

In the old days you had a communal area and several families lived around there. Whatever you cooked other people would smell it, then your neighbour would actually bring their bowl and come to you and just share a little bit saying, "come and have a taste". And it was all very common, and if you made some main course you would just cook for all of them [the neighbours]...that was very common at that time, now it would seem to be a bit odd if you knocked on other peoples' doors and just said, "would you like to try a bit [of food]?" 
Fu Rong continued to talk about life within the courtyard neighbourhoods, suggesting that basic conditions and a lack of modern amenities during this era also provided a stimulant for greater interaction amongst residents.

What I remember most in the old days, we'd have a communal area where I lived, and there were lots of children....and in the evening during the summer time, because there weren't any air conditioners, we'd have to stay in the communal area to get cool. There was a large tree in the middle which everyone sat around listening to ghost stories.

The sky well structures and communal areas can still be found within Suzhou's old town district; and integral to the walking ethnography methodology we were shown around exemplars of these structures by those local residents that remain in the old town. However, many of the courtyard residential neighbourhoods require restoration (see Figure 1), with a large majority having undergone commercial renovation used for the purpose of teahouses, restaurants or art galleries in attempt to stimulate the local tourist economy and draw capital from historic structures. ${ }^{6} \mathrm{Zhao} \mathrm{Fu}, \mathrm{a}$ retired teacher in his mid-sixties, further commented on the architectural layout of former communities and the literal connections that were sustained between his former home and that of other urban neighbourhoods.

So at your back door there was a lane, and the lane of somebody else's backdoor also led to your front door, so one after the other, one after the other, so it was all connected somehow.

[Insert Figure 1 about here]

The Suzhounese residents in this study felt these "connections" within the older urban communities fostered a sense of mutual assistance, local intimacy and strong sense of “neighbourliness" (Li et al. 2012; Liu et al. 2012; Xu et al. 2010). These markers of everyday life in older urban communities were partly dictated by the spatial composition and poorer conditions of

\footnotetext{
${ }^{6}$ As indicated in the methodology, part of the larger study comprised interview with elites (including city planners and those involved in historic preservation). The city's 'heritage' whilst protected, juxtaposed with the desire of municipal planners to accumulate capital from the old town district, a focus of a subsequent article.
} 
courtyard living, former features of urban China that promoted strong social ties between residents and aided in fostering a "sense of community". Wang Lei, a thirty-three-year-old Suzhounese resident, further reinforced the intimacy of the older urban neighbourhoods recounting his childhood memories of leisure/play in Suzhou's traditional old town district.

When we were kids we just played in the very narrow street...The lanes cut across very frequently so it's just like a maze, like a paradise for the kids...But, you know Youxiang [residential street] has already been broken.

Interviewer: How do you feel about that?

Wang Lei: It's a big pity...I think it [Youxiang] is very good and I still cherish it so much.

Interviewer: What made it so good?

Wang Lei: Just like, I've never been to Italy, but I can imagine if I walked through the streets in Italy it would be very narrow and the roads are built by old stone and you can see the history...It's a little bit smelly, not so fresh, the air there [Youxiang Road], but I can imagine if you live in that kind of place you can imagine how the grandfathers lived, so that's very important.

Reference to the 'broken' Youxiang neighbourhood is indicative of the new developments that have reshaped certain spatial configurations in the city's old town district. Whilst the 'historic core' of the district retains its cartographic_albeit increasingly tourist oriented-layout, the peripheries have become incorporated into the 'logics' of (trans-)national capital. Roads have been widened and courtyard compounds replaced or re-shaped by Western influenced commerce (see Figures $2 \&$ 3). The interviewees in this study saw such developments as 'breaking' established patterns of everyday life, human connection and trans-generational interactions in Suzhou's old town district. Our fieldnotes and immersion in this neighbourhood suggested that the use of space differed across the generations — older residents and some tourists for example seeking out historic local shops such as Huangtianyuan or Sanwanchang to purchase traditional street food whilst younger residents, 
with a seemingly transnational outlook, purchasing distinctly western goods and foods (from e.g. McDonalds, H\&M and Marks \& Spencer). Further, the data suggests the sensual experiences of everyday life within the courtyard neighbourhoods - specifically the smells of food, the quality of air and the 'imagined' heritage — in connection with the distinctive Suzhounese architecture and close proximity living aided in constituting and (re)affirming a sense of place. The residents' reflections upon the mundane sensual and material qualities of their urban histories were suggestive of distinct connections between their cultural lives and the space they inhabited, constituting a relational effect between the material (that is the built structures) and non-material constitutions of everyday life (Miller 1998).

[Insert Figures $2 \& 3$ about here]

Of course, 'community' is not simply reducible to a shared existence of physical space, the forging of strong social ties or the increased frequency of interaction within neighbourhoods. These elements are clearly aligned with the embodied details of inhabitation, the corporeal connections with architecture, the expression of place, and the shaping of urban experiences (Buttimer 1980; Dreyfus 1993; Ingold 2000; Sennett 1994). For the participants, community was expressed as a reciprocal relationship between human and non-human qualities that comprise the spatial and material aspects of urban 'dwelling' (Kraftl and Adey 2008; McFarlane 2011; Pons 2003). Closely aligned with the conception of urban assemblages, these (re)presentations of community existence are not just "a spatial category, output, or resultant formation, but signify doing, performance and events" (McFarlane 2011: 265). Thus, the qualities assigned to a sense of community were comprised of a network of shifting interactions and encounters between social actors, their relationships with architectural form, and a sensual engagement with the environment (Deleuze 2000; McFarlane 2011; Pons 2003). Here the unity of assemblage is characterised by the contingent relationship between such diverse elements, distorting the separation of the social-material (Anderson and McFarlane 2011; McFarlane 2011; McFarlane and Anderson 2011). Yet the physical 
transformation of urban China is an emergent process that is reshaping the nature of such interactions, a process that is disassembling and reassembling the socio-spatial composition of city space (Allen 2011). Alterations to China's urban form have come to represent the tensions between, "fixity and flow, stasis and change, integration and fragmentation, diversity and commonality" (Amin 2007: 104), aspects that portray community not simply as a continuous mass of interrelated elements, but developing through processes of "acceleration and rupture" (Deleuze and Guattari 2000), uprooting cultural values, (re)creating new patterns of movement and differing modes of local social interaction (Amin and Thrift 2008; Dewsbury 2001). Such transformation became most evident amongst the residents when discussing the loss of a particular way of life pertinent to their own 'authentic' representations of Suzhounese identity.

\section{Transforming Communities}

Urban transformations have clearly impacted upon neighbourhood interaction, altering everyday lives and the 'doing' and 'performing' of community (McFarlane 2011). Residents emphasised subjective and emotional attachment to a 'sense of place' (Creswell 2004), with notions of community heavily imbued with a sense of belonging grounded in the performance of a particular Suzhounese lifestyle. For example, Yi Sheng, a retired doctor in his early-seventies, suggested the 'old ways of living' in a 'collective living environment' formed an integral aspect of his cultural identity:

Our old lifestyle is because Suzhounese really pay attention to detail, everything is in order, our lifestyle, our food, our habits are all in a very detailed order. For example, in the old days we would get up in the morning have a bowl of noodles and in the afternoon you'd go to a public bath, and in the summer time it would be hot so everyone would sit outside and have a chat about what's new ... we would really pay attention to these things ... such kind of a lifestyle now only forms part of a memory, it's impossible to live like that now. 
For Yi Sheng, the construction of a sense of place was intimately linked to memories of a former lifestyle, one that was described as impossible within modernizing urban China. The sense of belonging and an affinity to the city as a mark of identity — what it meant to be a 'true' Suzhounese resident-was a construct not cultivated from a top down approach but fostered through, "the "bottom up" experiences of ordinary people's everyday lives" (Mathews et al. 2008: 146). Similarly, Yi Hu spoke of the ways in which people historically interacted through the trading of goods from the transportation networks on the city's ancient waterways:

A typical lifestyle for the old days is how we used to buy food. You'd have a basket with a rope connected to it and you'd just lower down your basket, and people selling vegetables would be all along the canal. So you lower down your basket buying vegetables and people were selling them on the boat, buying and selling food just like that, just like a river market. That was typical for Suzhou, you could only see that around here.

In describing community, the residents' often referred to the past, re-imaging a particular way of life that they deemed "typical" of Suzhounese culture. They placed importance upon the intimate and informal everyday manner in which interactions took place, performances that worked to reaffirm a sense of place deemed to be "authentic" (Brown-Saracino 2004). Whilst the residents" interpretations of authenticity were important to acknowledge in the changing face of local tradition and social interactions, this proposed representation of an "authentic past" was, for the majority of interviewees, wedded to a specific moment in time that portrayed particular cultural practices distinctive to their own experiences, thus (re)producing perceptions of an "authentic" community identity in the face of multiple possibilities (Zukin, 2009, 2010). Fu Rong further reflected upon the common customs, leisure activities and specific social encounters that framed everyday life within Suzhou's historic core.

In the old days when people were selling flowers, they were selling flowers by singing it, and the song was sung in a very traditional tone from the area. Instead of just shouting it was 
actually sung as a song, "zhi zi hua bai lan hua" [sings the words "gardenia and magnolia" in Suzhounese dialect and with the traditional tone]. So when you were staying at home, hearing people walking pass-by selling these, in the meantime you are also hearing a poem or a song, and that was typical to Suzhou.

The retelling of past memories and reminisces of everyday urban life allowed residents to voice a range of individual stories that spoke to historical experiences of community, highlighting the impact that urban transformation has imposed upon patterns of local social interaction, cultural practices and place identity (Chang 2005). These experiences of nostalgia, of remembering, were often sensory; residents espoused particular smells, tastes, physical and somatic effects, responses that emphasized the interconnections between bodies, places and minds (Farrar 2011). In many respects, these affective dimensions of community and belonging return us to the pioneering work of Robert Park (1915), reminding us that to understand the city —and thus neighbouring communities - we need to draw on methodologies that literally can get under the skin of its human residents (Park 1915). This aids us in thinking about city space as constituting a dynamic and complex relationship between its physical organization and the human nature that carves its characteristics, a process where "the city takes on something of the character and qualities of its inhabitants ... inevitably stained with the peculiar sentiments of its population" (Park 1915: 579). The mutual constitution between the embodied/performative and the physical constructs of city space portrays communities as a living organism in which social relationships become expressed through local character, common feelings and ways of thinking (Tönnies 1955). However, such relations exist within a constant state of transformation; the living organism is never still, it is always in flux, in part subject to the structural organisation of the city and the fluid movement of people who inhabit it. Changing social relations instigated through the rapid development of the city were emphasised by participants in this study, who described the impact of Suzhou's modern SIP district upon intergenerational interactions: 
It's [the SIP] a completely new lifestyle, in the old town all the elderly people live there and the living conditions are quite poor, and I feel that's quite a shame as the younger generation have all moved out of the old town (Yi Hu).

I go to the Old Town every week to see my mother. In the Old Town there are still so many old people living there, they are remaining there, and haven't moved, because for them the lifestyle is always the same they don't want to change (Fu Rong).

Participants spoke emotively (and visually referred) to the relationships between historical memories/portraits of place, 'coherent' identities and the making of 'community'. Using photographs of his former home (see Figure 4), Zhao Fu, for example, addressed transformations in Suzhou's old town, the loss of particular neighbourhoods, and the importance of preserving the city's historic built structures to retain a sense of identity and attachment pertinent to his experiences of the city:

When I was little I lived in the old city, by a very old alley, like a small road. The house was a 'Western' style house [shows us the picture of his old house]...over ten families stayed in this old 'Western' style house ... there were local markets, but it was a residential area as well, you know Chinese people at that time all go to shop at local markets where people just sold vegetables and fish within a small area. At the moment the house is still standing there but the area is going to be demolished, now it is marked as a dangerous area ... It's very important that we preserve the old town's history, without the old city Suzhou will no longer be Suzhou, it will have lost its meaning.

[Insert Figure 4 about here]

In mourning the past, and within an urban assemblage understood through rapid social transformations and complex interactions between local and globalizing tendencies, structures and forces, these comments are suggestive of a searching for 'roots' and the desire to (re-)affirm 
coherent community identities (Hoelscher and Alderman 2004). Zhao Fu's concerns over the loss of specific neighbourhoods/lived culture represents wider patterns of planning policy and accelerated city growth within China. Spatial reconfigurations have eliminated certain aspects of China's built heritage, a process that has gradually contributed towards the destabilising of place-based meanings and reshaped a particular way of life for many of the nation's urban residents (Zhou et al. 2010; Zhu et al. 2014). For Suzhou, and as expressed in these data, despite, if not because of, the transformation of certain quarters of Suzhou's old town, the importance of preservation of the historic core of the city remains paramount. Preservation of residential structures, configured in relation to historic waterways that have remained mostly unaltered since the city's conception, are seen as the last bastion of identity, of culture, of community. Further destruction of these spacesand we would add, the manipulation of such spaces in the name of capital/heritage (see Graham 2002) — would, for the residents, mean the palpable loss of cultural values closely aligned to the performance/doing of a particular way of life. These affective and embodied elements of community, intangible qualities connected to Suzhou's cultural heritage and strong sense of community, were an aspect of urban living perceived difficult to replicate within the modern development zones of the city and the broader field of contemporary Chinese society.

\section{Accelerated Growth / Urban Sprawl}

As is clearly expressed above, the data in this study suggest that physical transformation of Suzhou's older urban neighbourhoods has had a profound effect on neighbourly interactions and local social relations amongst community members (Forrest and Yip 2007; Wang et al. 2015; Wu and $\mathrm{He}$ 2005), one in which older residents romantically spoke about a (mythologised) past in which community was mutually constituted through bodies/spaces. Accelerated growth, accompanied by the influx of migrant populations to Suzhou and the contemporary development of modern districts, has further complicated the complexity of urban form and fostered an increased 
hybridity amongst its urban population. As with other Chinese cities, the construction of gated communities within large-scale suburban developments has brought about the relocation of many residents from the old urban areas to the periphery, resulting in improved infrastructure, but only for those with the capital and means to invest in new property development. Within China more generally, growing social inequalities has become synonymous with the bifurcation of urban landscapes, marginalising lower-income families as they remain within inner-city urban neighbourhoods that often lack the modern amenities and access to lifestyle preferences and (transnational) aspirations that are associated with new residential developments (Pow 2009; Xu 2008). Accompanying urban transformations within the historic core, Suzhou has grown concentrically - city leaders refer to Suzhou with an ornithological metaphor, suggesting the historic core as the body, with an increasingly vast wingspan as the containers of accelerated urban growth - incorporating new, and often competing, districts that offer a mixture of high-rise housing, commerce and services. Again, through exorcising the past to make sense of the present, Yi Hu's narrative of community life within contemporary Suzhou's wingspan, was suggestive of a decline in social interaction and a lack of familiarity with those situated in her immediate community:

In the old days, when we'd live in the old town, we'd know all our neighbours around and we'd talk with them often, but that feeling has become much less nowadays, even in the old town. In the new town [SIP], absolutely nothing because we don't know our neighbours. But in the old days you knew everybody around and people were really friendly and kind.

In Suzhou, China's strategy for urban growth was felt to be impacting upon levels of community participation; as $\mathrm{Yi} \mathrm{Hu}$ identified, dissolving the feelings of attachment, collectivism and local social interaction between immediate neighbours. This shift towards ideals of (neoliberal) individualism and a middle-class consumptive ethic are, in part, stimulated by an increasingly heterogeneous and complex socio-spatial composition that is altering the manner through which community engagement is becoming structured (He 2013; Pow 2009; Wang et al. 2015). Fu Rong, 
for example, now residing in a gated commodity housing estate situated within Suzhou's SIP district, spoke to the changing nature of community interaction and the regulation and commodification of formalised community engagement and leisure opportunities:

There are a lot of community activities around each district. So each complex might have some community activities ... The facilities around here [SIP] have lots of variety; you can go to the gym, go swimming, dancing, all different kinds of things you can join ... compared with the old town, there the facilities are quite limited because of space and the buildings are old.

Interviewer: What about your connection with the people, how is that different?

Fu Rong: There is definitely a big difference. If you are in the old town, where I grew up, there were fifteen children and we would have a memo for that building, or maybe complex, and in the summer time we would organise some activities or functions that we could all do together, probably play some instruments where each of us would have a performance. It was full of fun we had lots of interaction with our neighbours. But here if you are not going to attend the public community activities then you will have no interaction with your neighbours, you will just stay at home ... Now you have to schedule activities, you have to tell your friends to meet on such and such a date, obviously in the old times we could just walk around, turn a corner, and you could find your neighbours and you could have a chat. According to $\mathrm{Fu}$ Rong, residing in newly developed commodity-housing estates suggests the absence of (or little) interaction with their neighbours, suggestive of increased instances of social isolation and the breakdown of community-ties that were once affiliated with the former danwei compounds, hutongs or shikumen (Farrer 2002; Fleischer 2007; Pow 2009; Wu 2009).

To suggest that community engagement has become a redundant feature of more complex and contemporary Chinese city spaces, would however present an oversimplification of the complex socio-demographic component that comprises emerging and established urban enclaves 
(He 2013). As Fu Rong indicated, participation within community leisure-based activities still form an integral component of everyday life within Suzhou's modern SIP district. Gated commodityhousing estates provide spaces for engagement; however, such urban environments are often heavily securitised, enclosed and available only to private residents (see Figure 5). Thus, for Fu Rong, the process of interaction was facilitated through the active and formal arrangement of community activities within the public spaces provided outside the walls and security barricades of gated housing. This is perhaps unexpected; improved infrastructure and public leisure facilities within China's developing cities have increased levels of mobility, and thus encouraged social interaction to take place beyond the physical boundaries of their immediate communities (Breitung 2012; He 2013). However, such patterns of interaction are suggestive of a decline in collectivist cultural traditions, a shift towards a consumptive leisure ethic, the ways in which communities of people are engaging with one another, and the sociospatial separation of certain aspects of everyday life (leisure, work, shopping) (Wang et al. 2012). Wang Lei, having moved from an old district within Suzhou to the modern SIP development zone, commented on the changing importance attached to notions of community under the auspices of an increasingly emergent individualised logic:

Wang Lei: Most of the family don't even consider things for themselves, they are always considering things for their children ... my parents moved to Suzhou's SIP when I was about 11 years old. And the purpose of them to migrate, you can say, is just to provide me with a better life.

Interviewer: But it's important to have a community around you, isn't it?

Wang Lei: Actually, you know community or communication is very important, but it's nothing compared to my own personal development. If I can develop myself in a much better way, in a new place, then I'll move there.

[Insert Figure 5 about here] 
Further, Pan Wei, a resident in her mid-fifties, pointed to the changing nature of interaction amongst contemporary communities within Suzhou's old town, reinforcing the importance of immediate familial ties:

Pan Wei: We all live in individual flats, so we hardly see our neighbours or interact with them, so we don't really care about who are neighbours are. After work I just come home and spend the rest of my time with my family, but in the old days when we were living in the house there were loads of families around and kids all played together ... we would arrange to visit the gardens all together, or arrange to go to the zoo, but now it is something we wouldn't do with our neighbours because we don't know each other.

These seem important shifts in the conceptualisation of community within contemporary Chinese city spaces. At their extreme, these comments speak to a loss of, if not disdain for, community at the expense of an individualised (consumptive) ethic. Contemporary (inter)relationships between community attachment, the built environment and cultural traditions, connected to the wider sociopolitical context driving China's urban growth and development ( $\mathrm{Li}$ et al. 2012), suggest a shift away from encompassing conceptualisations of community. Indeed, suburban residential developments and commodity-housing complexes are portrayed as providing a 'good life' for their customers (and their families) and signify progress, development and an engagement with new (transnational) life-style products that carry the values of choice, diversity and conspicuous consumption (Wu 2010). Participants then spoke of the positive benefits of residing within modern complexes situated within Suzhou's SIP district, citing the improved infrastructure, public facilities, open space, clean air, and convenient amenities as important conditions in framing their opinions. For Wang Lei, as with many of China's younger generation, embracing the new lifestyle associated with modern residential developments symbolised a significant departure from the traditions of older urban neighbourhoods and the rural poor, and a growing desire to embody values akin to affluence, exclusivity and China's 'civilised modernity' (Pow 2009; Shen and Wu 2012). Notably, 
within these comments, community was conceptualised differently than when speaking to older social forms, structures and interactions. There was a marked absence of the affective, of the emotive; respondents instead speaking to the more clinical, sanitised and productive features of a progressive growth rhetoric (secure, clean and individualised as opposed to smells, tastes and interaction).

There also appeared an increasing intergenerational chasm in relation to the affective sense of place reflected upon by older citizens associated with everyday life in historic urban forms/structures. With the rise of modern housing complexes in the urban periphery, many of the older residents interviewed expressed concern for the 'former way of life,' and a fear that younger generations will no longer inherit, understand or engage with cultural traditions associated with Suzhounese heritage. For example, Yi Sheng spoke of his concerns regarding the gap between generations, Suzhou's changing urban form, and the preservation of cultural heritage:

We are the last generation that can experience both old and new; the younger generation, they were born in the old times, but they were too young to remember these old [life]styles. So when our generation passes away no one will be able to talk about the old style other than just reading it in a book, that will be the only place you can find the old style, the old way of life.

With a desire to preserve the past—intricately and cautiously connected with the desire to extract capital from historic urban forms-Yi Sheng spoke to the potential (albeit not total) obliteration of particular notions of community. It is in this sense that we can identify how China's urban transformation has reshaped socio-spatial interactions and the manner through which community activities and engagement are enacted. What seems to be of importance for the residents interviewed was not necessarily the decline in interaction, nor the opportunity to engage with activities, but the loss of specific cultural conditions that framed a particular way of being. In this sense, the concept of community was not only associated with notions of 'spatial contiguity' (Amin, 
2007), but also with the affective, sensual and mundane experiences and feelings (the performance and doing) of community that connect beyond the boundaries of physical space. For the residents interviewed, the city of Suzhou was viewed as an archive for cultural memory (Hetherington 2013), and brought forth the importance of considering cultural conditions that contribute towards a sense of attachment and identity, aspects that are often overlooked within studies examining China's transforming cityscapes (Zhu, Qian, and Feng 2011; Wu and Ma 2006).

\section{Conclusion}

Suzhou's push towards modernity—created and enacted by a complex assemblage involving coevolving governance projects, strategies, and practices framed by both national and transnational scales (McGuirk and Dowling 2009) — has (re)shaped and regulated the everyday lives of residents. Through an integrated methodological approach, we have been able to offer rich narratives of attendant values, experiences and behaviours attached to notions of community, both past and present. In so doing, and with reference to the Iain Sinclair quote with which we opened the paper, we point towards the diminished role of the affective in conceptualising community as deep cultural attachment or performance; the 'doing of community' replaced with a more sanitised, securitized, and sober individualised ethic. These processes are perhaps best understood as a complex relationship between a multiplicity of parts each guided by their own determinations, neither static nor fixed by singular points of contact, but altering through reactive transformations to wider policy changes and the unravelling or encountering of emerging institutional relations. Drawing on Deleuze and Guattari's (2000) notion of the 'assemblage', we can frame Suzhou's urban development — as we argued previously, as emblematic of China's urban spaces — and growth as, "an amalgam of often disjointed processes and social heterogeneity, a place of near and far connections, a concatenation of rhythms" (Amin and Thrift 2008: 8). Here then urban assemblages are not bound by a specific temporality; as such new potentialities, either as material or intangible, 
should be considered with reference to proceeding historical processes and their enactment upon the manner through which sites and actors are infused, aligned or dispersed (McFarlane 2011). Put simply, cities and the communities they house consist of a multiplicity of beings that are products of collective histories, nested within one another and guided by wider socio-political forces that shape or maintain the local dynamics contributing towards contemporary urban relations (Amin and Thrift 2008; DeLanda, Protevi and Thanem 2005; Ren and Luger 2015).

As demonstrated in previous research (Forrest and Yip 2007; Liu et al. 2012; Wu 2012), the Suzhou data reaffirmed the decline in neighbouring activities, with attention shifting away from communal living and a shared existence of everyday urban life. Whilst previous research has identified differing patterns of neighbourhood social interaction within China's urban communities (Douglas et al. 2012; Li et al. 2012; Wang et al. 2012; Wu 2012), a common theme in our analysis related to the lack of familiarity amongst residents living in both the old town district and commodity-housing complexes. The residents' reflections upon local social interaction demonstrated that a lack of familiarity, willingness, and opportunity to engage with immediate neighbours has become increasingly common under the auspices of 'development'. The commodification of urban space, increased mobility of rural migrants (see $\mathrm{Wu} 2012$ ) and the movement of residents away from Suzhou's old town to the modern SIP district are primary influencers contributing towards an increasingly heterogeneous society and shift in community relations. This is not to suggest that interaction and engagement has become non-existent within Suzhou's urban neighbourhoods; rather that informal interaction has become increasingly formalised.

Conceptual analysis also pointed towards increasing generational difference with respect to the preservation of community, architecture and ways of life. Therefore, and in conjunction with the work of Zukin $(2009,2010)$, there is a need to further locate the socio-cultural and political contexts in which these recollections of city experience arise to help contextualise and comprehend the 
selective nature of social memory in relation to reflections on community life in urban China. The longing and expression of nostalgia from all residents interviewed provided an avenue to maintain a sense of emotional continuity to the city, whereby the re-telling of former memories and cultural practices connected to the affective experiences of community life evoked a strong sense of identity amidst rapid alterations to personal and social lives (Adams and Larkham 2016). The acquisition of urban memories, and the narratives they entail, allows for a clearer depiction of differing cultural and social identities arising as a consequence of China's strategy for growth and development. Thus, the manner through which varied communities perceive their past may reveal further insight into the way in which residents, planners and policy makers manage their present and embrace the future (Chang and Huang, 2005). Moreover, to sustain and nurture sensory connections with place - an attachment to community that was garnered through differing feelings, habitual activities and routines - the preservation and conservation of older neighbourhoods is integral to maintaining a sense of identity (although, is potentially harmful if reduced to preservation for the tourist gaze). The process of conservation is vital to giving voice to fading cultural traditions, as the materiality of the past maintains the capability to not only speak to the present but provides an opportunity to shape and enlighten potential alternative urban futures and stimulate the awakening of a culture-led regeneration (Hetherington 2013).

It has been our intention throughout this paper to uncover the core components that frame contemporary conceptions of 'community', and identify the shifting patterns of local social interaction amongst residents living in China's urban neighbourhoods. We sought to emphasise the importance of considering historical continuities, intangible cultural traditions and the affective and sensual qualities that connect residents to a sense of place. However, and whilst we understand Suzhou as emblematic of the processes re-shaping China's urban spaces, we are mindful of the very different social and cultural geographies of these urban spaces. We thus suggest the need for further scholarship that can uncover the sensual and affective dimensions of community over time that can 
capture the day-to-day social dimensions of residents' lives, and gather the experiences and voices of (marginalised) populations who might otherwise remain unheard (Hetherington 2013). Such insight will further enhance our understanding of the impact of accelerated urban growth and development on culture, community and citizens. In this regard, we are suggesting that through 'thinking assemblages' (Dewsbury 2011), a planning/development approach can be adopted that pays heed to the alterations and shifting patterns of interaction between sites and actors, ideologies, collective histories and the institutional relations that seek to produce, structure and remake the social (McFarlane 2011). By adopting this perspective emphasis is placed less upon identifying specific parts that comprise communities and more upon the altering (inter)relations between individuals, their surroundings and the affect that such transformations can bring about (Deleuze and Guattari 2000).

\section{References}

Adams, David, and Peter Larkham. 2015. "Walking with the Ghosts of the Past: Unearthing the Value of Residents’ Urban Nostalgias.” Urban Studies. doi: 10.1177/0042098015588683

Allen, John. 2011. "Powerful assemblages?” Area 43(2): 154-157.

Amin, Ash. 2007. "Rethinking the Urban Social." City 11(1): 100-114.

Amin, Ash, and Nigel Thrift. 2008. Cities Reimagining the Urban. Cambridge: Polity Press.

Anderson, Ben, and Colin McFarlane. 2011. “Assemblage and Geography.” Area 43(2): 124-127.

Arrighi, Giovanni. 2007. Adam Smith in Beijing Lineages of the Twenty-First Century. London: Verso.

Banks, Marcus, and David Zeitlyn. 2015. Visual Methods in Social Research. London: Sage. 
Bell, Duncan S A. 2003. Mythscapes: “Memory, Mythology, and National Identity.” British Journal of Sociology 54(1): 63-81.

Breitung, Werner. 2012. "Enclave Urbanism in China: Attitudes Towards Gated Communities in Guangzhou.” Urban Geography 33(2): 278-294.

Brown-Saracino, Japonica. 2004. "Social Preservationists and the Quest for Authentic Community." City \& Community 3(2): 135-156.

Cartier, Carolyn. 2001. “'Zone Fever', the Arable Land Debate, and the Real Estate Speculation: China's Evolving Land Use Regime and its Geographical Contradictions." Journal of Contemporary China, 10: 445-469.

Chang, Tou Chuang. 2005. "Place, Memory and Identity: Imaging 'New Asia'." Asia Pacific Viewpoint 46(3): 247-253.

Creswell, Tim. 2004. Place: A Short Introduction. Oxford: Blackwell.

DeLanda, Manuel, John Protevi, and Torkild Thanem. 2005. "Deleuzian interrogations: A conversation with Manuel DeLanda and John Protevi." Journal of Critical Postmodern Organization Science 3(4): 65-88.

DeLyser, Dydia. 2004. "Recovering Social Memories from the Past: The 1884 Novel Ramona and Tourist Practices in Turn-of-the-Century Southern California." Social \& Cultural Geography 5(3): 483-496

Douglas, Mike, Bart Wissink, and Ronald Van Kempen. 2012. "Enclave Urbanism in China: Consequences and Interpretations." Urban Geography 33(2): 167-182.

Dwyer, Owen J, and Derek H Alderman. 2008. "Memorial Landscapes: Analytic Questions and Metaphors.” GeoJournal 73: 165-178.

Edensor, Tim. 1997. "National Identity and the Politics of Memory: Remembering Bruce and Wallace in Symbolic Space.” Environment and Planning D: Society and Space 15(2): 175-194. 
Edensor, Tim. 2010. "Walking in Rhythms: Place, Regulation, Style and the Flow of Experience." Visual Studies 25(1): 69-79.

Forrest, Ray, and Ngai-Ming Yip. 2007. "Neighbourhood and Neighbouring in Contemporary Guangzhou." Journal of Contemporary China 16(50): 47-64.

Halbwachs, M. 1980. The Collective Memory. New York: Harper \& Row.

Harvey, David. 2005. A Brief History of Neoliberalism. New York: Oxford University Press.

He, Shenjing. 2013. "Evolving Enclave Urbanism in China and its Socio-Spatial Implications: The Case of Guangzhou.” Social \& Cultural Geography 14(3): 243-275.

He, Shenjing, and Fulong Wu. 2005. "Property-Led Redevelopment in Post-Reform China: A Case Study of Xintiandi Redevelopment Project in Shanghai.” Journal of Urban Affairs 27(1): 1-23.

He, Shenjing, and Fulong Wu. 2009. “China's Emerging Neoliberal Urbanism: Perspectives from Urban Redevelopment.” Antipode 41(2): 282-304.

He, Shenjing, and Junxi Qian. 2017. From an emerging market to a multifaceted urban society: Urban China Studies. Urban Studies 54(4): 827-246.

Hetherington, Kevin. 2013. "Rhythm and Noise: The City, Memory and the Archive." The Sociological Review, 61: 17-33.

Hoelscher, Steven, and Derek H Alderman. 2004. "Memory and Palace: Geographies of a Critical Relationship.” Social \& Cultural Geography 5(3): 347-355.

Huang, Yasheng. 2008. Capitalism with Chinese Characteristics: Entrepreneurship and the State. New York: Cambridge University Press.

Latham, Alan, and Derek P McCormack. 2009. "Thinking with Images in Non-Representational Cities: Vignettes from Berlin.” Area, 41 252-262.

Leaf, Michael. 1997. “Urban Social Impacts of China’s Economic Reforms.” Cities 14(2): vi-vii.

Li, Fan, Zhu Hong, Wei Huang. 2010. “A Geographical Study on the Collective Memory of Urban Historical Cultural Landscape.” Human Geography 25(4): 60-66. 
Li, Si-Ming, Yushu Zhu, and Limei Li. 2012. "Neighborhood Type, Gatedness, and Residential Experiences in Chinese Cities: A Study of Guangzhou." Urban Geography 32(2): 237-255.

Liew, Leong. 2005. “China's Engagement with Neo-Liberalism: Path Dependency, Geography and Party Self-Reinvention.” Journal of Development Studies 41(2): 331-352.

Lin, George CS, and Samuel P S. Ho. 2005. "The State, Land System and Land Development Processes in Contemporary China." Annals of the Association of American Geographers 95(2): 411-436.

Lowenthal, David. 1975. "Past Time, Present Place: Landscape and Memory.” Geographical Review, 65(1): 1-36.

Lowenthal, David. 1985. The Past is a Foreign Country. New York: Cambridge University Press.

Mills, Amy. 2006. "Boundaries of the Nation in the Space of the Urban: Landscape and Social Memory in Istanbul.” Cultural Geographies 13: 367-394.

Mathews, Gordon, Eric Kit-wai Ma, and Tai-Lok Lui. 2008. Hong Kong, China: Learning to Belong to a Nation. London: Routledge.

McFarlane, Colin. 2009. “Translocal Assemblages: Space, Power and Social Movements.” Geoforum 40: $561-57$.

McFarlane, Colin. 2011. "Assemblage and Critical Urbanism." City: analysis of urban trends, culture, theory, policy, action 15(2): 204-224.

McFarlane, Colin, and Ben Anderson. 2011. “Thinking with assemblage.” Area 43(2): 162-164.

Miller, Daniel. 1998. Material Cultures: Why some Things Matter. London: UCL Press.

Pons, Pau Obrador. 2003. "Being-On-Holiday: Tourist Dwelling, Bodies and Place.” Tourist Studies 3(1): 47-66.

Park, Robert. E. 1915. “The City: Suggestions for the Investigation of Human Behaviour in the City Environment.” American Journal of Sociology 20 (5): 577-612. 
Pink, Sarah, Phil Hubbard, Maggie O’Neill, and Alan Radley. 2010. "Walking Across Disciplines: From Ethnography to Arts Practice.” Visual Studies 25(1): 1-7.

Pow, Choon-Piew. 2009. Gated Communities in China: Class Privilege and the Moral Politics of the Good Life. Abingdon, Oxon, UK: Routledge.

Ren, Julie, and Jason Luger. 2015. “Comparative Urbanism and the 'Asian City': Implications for Research and Theory.” International Journal of Urban and Regional Research 39(1): 145-156.

Ren, Xuefei. 2008. "Forward to the Past: Historical Preservation In Globalizing Shanghai." City \& Community 7(1): 23-44.

Ritzer, George. 2004. The Globalization of Nothing. Thousand Oaks, CA: Pine Forge Press.

Rose-Redwood, Reuben, Derek Alderman, and Maoz Azaryahu, M. 2008. "Collective Memory and the Politics of Urban Space: An Introduction.” Geojournal 73: 161-164.

Said, Edward. W. 2000. Invention, Memory, and Place. Critical Inquiry 26: 175-192.

Sennett, Richard. 1994. Flesh and Stone. London: Faber and Faber.

Shen, Jie, and Fulong Wu. 2012. "The Development of Master-planned Communities in Chinese Suburbs: A Case Study of Shanghai’s Thames Town.” Urban Geography 33(2): 183-203.

Wang, Donggen, Fei Li, and Yanwei Chai. 2012. "Activity Spaces and Sociospatial Segregation in Beijing.” Urban Geography, 33(2): 256-277.

Wang, Fenlong. And Yungang Liu. 2015. "How Unique is 'China Model': A Review of Theoretical Perspectives on China's Urbanization in Anglophone Literature." Chinese Geographical Science 25(1): 98-112.

Wang, Ya Ping, and Alan Murie. 1999. "Commercial housing development in urban China.” Urban Studies 36: 1475-1494.

Wang, Lei, Jianfa Shen J, and Calvin King Lam Chung. 2015. "City Profile: Suzhou - A Chinese City under Transformation." Cities 44: 60-72. 
Wang, Zheng, Fangzhu Zhang, Fulong Wu. 2015. "Intergroup Neighbouring In Urban China: Implications for the Social Integration of Migrants." Urban Studies. doi: $10.1177 / 0042098014568068$

Wei, Dennis. Y. H, Yuqi Lu, Wen Chen. 2009. “Globalizing Regional Development in Sunan, China: Does Suzhou Industrial Park fit a Neo-Marshallian District Model?” Regional Studies, 43(3): 409427.

Wu, Fulong. 2006. “Globalization and China's New Urbanism”. pp. 1-18 in Globalization and the Chinese city, edited by F, Wu. London: Routledge.

Wu, Fulong. 2008. “China's Great Transformation: Neoliberlaization as Establishing a Market Society." Geoforum 39: 1093- 1096.

Wu, Fulong. 2009. "Neo-Urbanism in the Making Under China's Market Transition." City: analysis of urban trends, culture, theory, policy, action, 13(4): 418-431.

Wu, Fulong. 2010. "Gated and Packaged Suburbia: Packaging and Branding Chinese Suburban Residential Development." Cities 27(5): 385-396.

Wu, Fulong. 2012. "Neighborhood Attachment, Social Participation, and Willingness to Stay in China's Low-Income Communities.” Urban Affairs Review 48: 547-570.

Wu, Fulong, Shenjing He. 2005. "Changes in Traditional Urban Areas and Impacts Of Urban Redevelopment: A Case Study Of Three Neighbourhoods In Nanjing, China.” Journal of Economic and Social Geography 96(1): 75-95.

Wu, Fulong, and Laurence JC. Ma. 2006. “Transforming China's Globalizing Cities.” Habitat International 30: 191-198.

$\mathrm{Xu}$, Feng. 2008. "Gated Communities and Migrant Enclaves: The Conundrum for Building “Harmonious Community/Shequ”.” Journal of Contemporary China 17(57): 633-651.

Xu, Qingwen, and Julian C. Chow. 2006. "Urban Community in China: Service, Participation, and Development.” International Journal of Social Welfare 15(3): 198-208. 
Xu, Qingwen, Douglas D Perkins, and Julian Chun-Chung Chow. 2010. "Sense of Community, Neighbouring and Social Capital as Predictors of Local Political Participation in China." American Journal of Community psychology 45(3-4): 259-271.

Xu, Yinong. 2000. The Chinese City in Space and Time: The Development of Urban Form in Suzhou. Hawai'i, US: University of Hawai'i Press.

Yang, Daniel You-Ren, and Hung-Kai Wang. 2008. "Dilemmas of Local Governance under the Development Zone Fever in China: A Case Study of the Suzhou Region.” Urban Studies 45: 10371054.

Yeh, Anthony Gar-On, Xueqiang Xu, and Huaying Hu. 1995. "The Social Space of Guangzhou City, China." Urban Geography 16: 595-621.

Yi'En, Cheng. 2013. “Telling Stories of the City: Walking Ethnography, Affective Materialities, and Mobile Encounters." Space \& Culture, 17(3): 211-223.

Yip, Ngai Ming. 2012. "Walled Without Gates: Gated Communities in Shanghai.” Urban Geography 33: $221-236$.

Zhang, Li. 2010. In Search of Paradise: Middle-Class Living in a Chinese Metropolis. Ithaca, NY: Cornell University Press.

Zhou, Shang-Yi, Li-Ping Wu, and Wei-Chao Yuan. 2010. "The Relation of Landscape Representation Power and Local Culture Succession: A Case Study of Landscape Changing in an Old Commercial District of Beijing.” Human Geography 25(5): 1-5.

Zhu, Hong, Junxi Qian, J, and Lei Feng. 2011. "Negotiating Place and Identity after Change of Administrative Division.” Social \& Cultural Geography 12(2): 143-158.

Zhu, Hong, Xiaoliang Chen, and Junxi Qian. 2014. "Charting the Development of Social and Cultural Geography in Mainland China: Voices from the Inside." Social \& Cultural Geography 15(3): 255-283. 
Zuking, Sharon. 2009. "Changing Landscapes of Power: Opulence and the Urge for Authenticity." International Journal of Urban and Regional Research 33(2): 543-553.

Zukin, Sharon. 2010. Naked City: The Death and Life of Authentic Urban Places. New York: Oxford University Press.

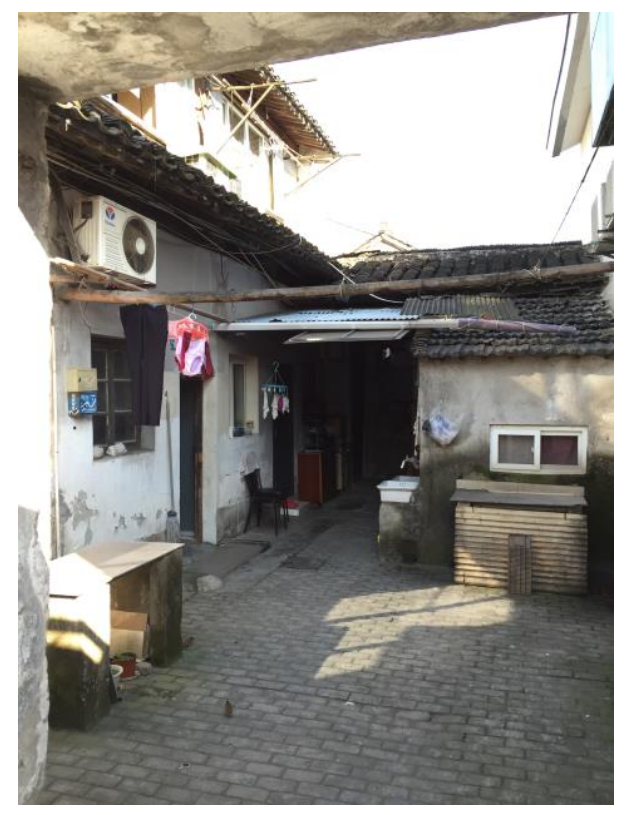


Figure 1: A typical tianjing communal area within Suzhou's old town district

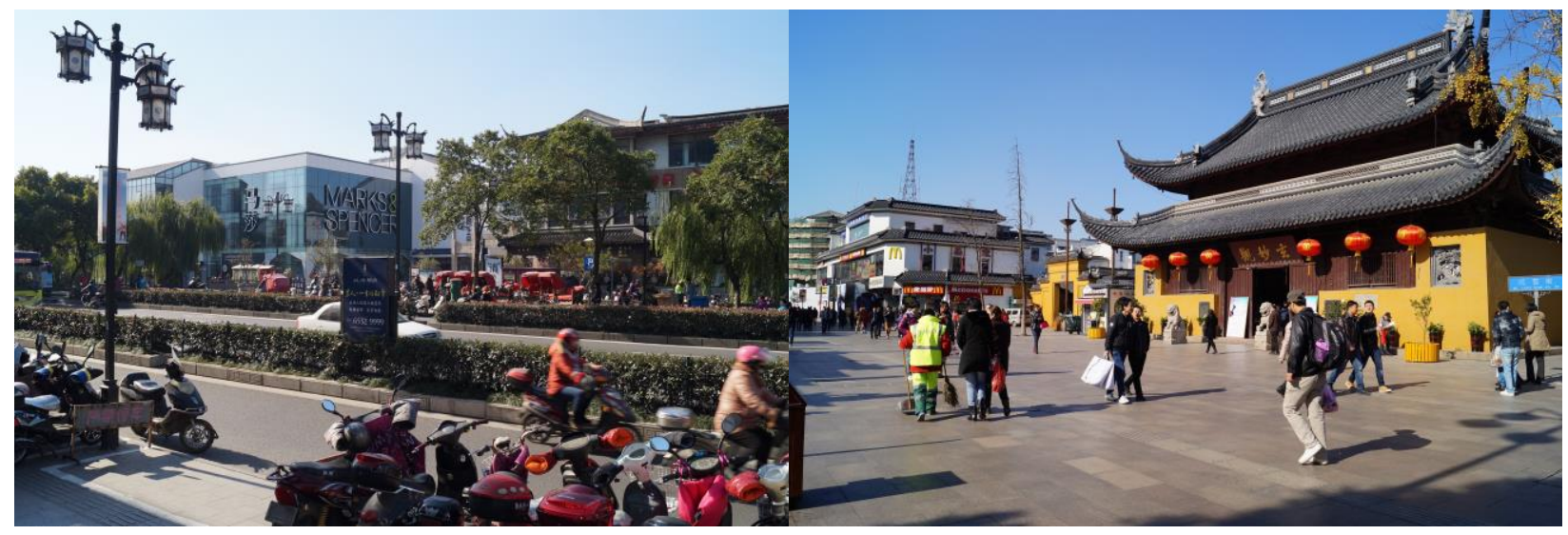

Figures 2 \& 3: Guanqian Street, Suzhou.

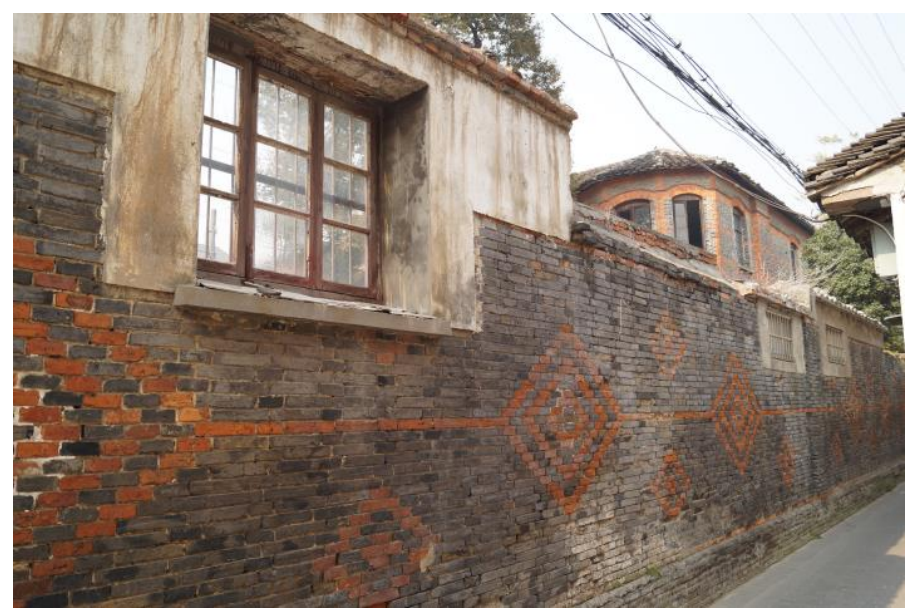

Figure 4: Participant's former residence now earmarked for demolition

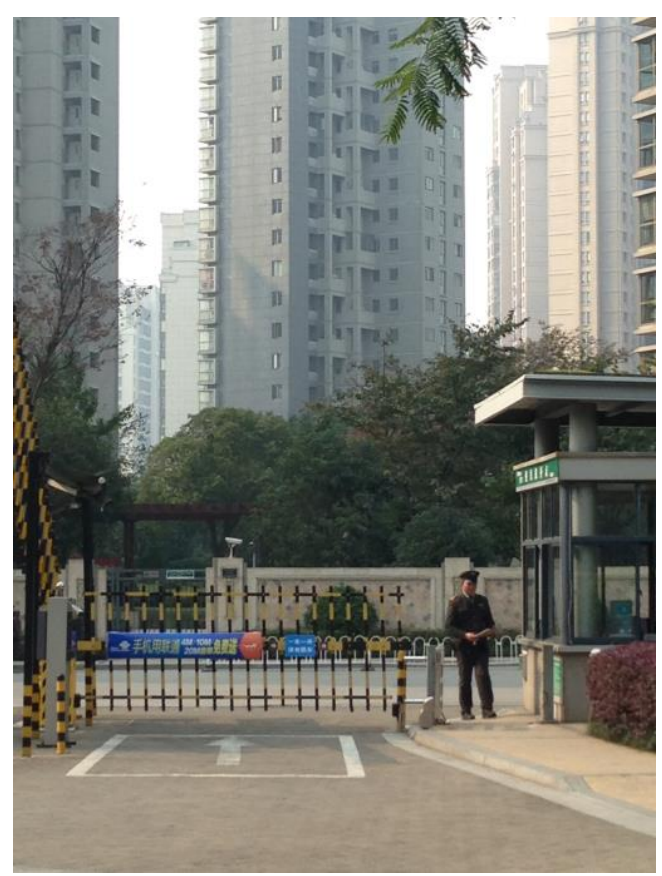


Figure 5: A typical gated commodity-housing estate in Suzhou's SIP district 